\title{
Monitoring and Trapping Insects on Poinsettia with Yellow Sticky Card Traps Equipped with Light-emitting Diodes
}

\author{
Tian-Ye Chen ${ }^{1,3}$, Chang-chi \\ $\mathrm{Chu}^{1}$, Thomas J. Henneberry ${ }^{1}$, \\ and Kai Umeda ${ }^{2}$
}

ADDITIONAL INDEX WORDs. yellow sticky card trap, light-emitting diode, greenhouse, poinsettia, insects

\begin{abstract}
SUMMARY. Insects in a commercial poinsettia (Euphorbia pulcherrima) greenhouse were monitored with yellow sticky card (YC) traps and YC equipped with 530-nm lime green light-emitting diodes (LED-YC) traps from 3 June to 25 Nov. 2002. Pest insects were: dark-winged fungus gnat (Bradysia coprophila), sweet potato whitefly (Bemisia tabaci) biotype B (= $B$. argentifolii), western flower thrips (Frankliniella occidentalis) and leafhopper (Empoasca sp.). Natural enemies were: minute pirate bug (Orius tristicolor), parasitic wasps (Hymenoptera), and rove beetles (Staphylinidae). Over the 24 weeks of the experiment, LED-YC traps captured more dark-winged fungus gnats, sweet potato whiteflies, leafhoppers, and rove beetles compared with YC traps. Capture of western flower thrips, minute pirate bugs, and parasitic wasps were not significantly increased on the YC traps equipped with LEDs. The results indicate that the LEDYC traps attract three major pest insects in poinsettia greenhouses and
\end{abstract}

${ }^{1}$ USDA-ARS, Western Cotton Research Laboratory, 4135 E. Broadway Rd., Phoenix, AZ 85040-8803.

${ }^{2}$ Maricopa County Cooperative Extension, University of Arizona, 4341 E. Broadway Rd., Phoenix, AZ 85040-8807.

We thank Roger M. Rapanut of McK Greenhouses Company, Mesa, Ariz., for his generosity of providing the poinsettia greenhouse for this study. Twanee Wilbur, Amy Opper, and Otto Isensee helped with insect counting. We appreciate the constructive review of the earlier version of the manuscript by Tong-Xian Liu and Alvin Simmons.; and we thank the two anonymous reviewers for their critical comments.

${ }^{3}$ To whom reprint requests should be addressed. E-mail address: tchen@wcrl.ars.usda.gov 
do not catch more beneficial, minute pirate bugs and parasitic wasps, but may catch significant number of rove beetles. The results suggest that LED-YC traps may be useful to monitor and reduce pest populations in greenhouses.

S everal insect pest species occur on poinsettia. Whiteflies and fungus gnats are common pests on greenhouse crops, including poinsettia. Whiteflies feed on leaves and cause leaves to become chlorotic. Whiteflies can also excrete honeydew on leaves, which provides a good substrate for sooty molds. Fungus gnats population can be a nuisance to greenhouse workers. The fungus gnat larvae fed on rootlets and may burrow into the lower stem of plants that promotes decay and collapse of the tissue. Thrips and leafhoppers are minor pests on poinsettia. At the same time, some beneficial insect species occur on poinsettia. Minute pirate bugs are predators of many pest insects including some lepidopteran eggs and small larvae, thrips, whiteflies, mites, and aphids (Knutson and Ruberson, 1996). Rove beetles feed on various species of small, soft-bodied insects and insect eggs. Hymenopteran wasps are parasites of many pest insects.

Light-emitting diodes (LEDs) are solid state, semiconductor light sources, and have some specific properties, including small size, low weight, high mechanical stability, low temperature sensitivity, high reliability, long operating lifetime, and low costs (Gillessen and Schairer, 1987; Schubert, 2003). LEDs have been used in many applications, such as numeric displays, status indicators, flat screens, remote controls, optical communications etc. (Gillessen and Schairer, 1987; Schubert and Yao, 2002). Insect light traps have been used for sampling various species of insects. However, few studies have been conducted to evaluate insect response to light produced by LEDs. Weber (1989) reported that light from green LEDs was more attractive to larval northern house mosquitos (Culex pipiens) than light from incandescent lamps. In field evaluations of colored LEDs as attractants for woodland mosquitoes, Burkett et al. (1998) found that several species of mosquitoes showed significantly different color preferences. Yellow sticky card (YC) traps have been used to monitor and reduce populations of whiteflies and other pests in greenhouses (Ekbom and $\mathrm{Xu}, 1990$; Gillespie and Quiring, 1987; van de Veire and Vacante, 1984). Equipping the standard plastic cup traps, also known as the CC traps, with lime green LEDs increased CC trap efficacy for sweet potato whiteflies (Chu et al., 2003). In the present greenhouse studies we compared YC and LED-YC trap catches of pest insects and natural enemies in a poinsettia growing greenhouse.

\section{Materials and methods}

Greenhouse. The studies were conducted in a commercial $47.2 \times 72.8$ $\mathrm{m}(155 \times 239 \mathrm{ft})($ width and length) poinsettia greenhouse in Queen Creek, Ariz., from 3 June to 25 Nov. 2002. The poinsettia cultivars were a mixture of 'Freedom Marble', 'Freedom Pink', 'Freedom Red', and 'Freedom White' (supplied by Eckepoint, Encinitas, Calif.). Rooted poinsettia cuttings were planted in $18 \times 20 \mathrm{~cm}(7.1 \times 7.9$ inches) round (height and diameter) plastic pots containing growth media (70\% peat moss, $20 \%$ perlite, and $10 \%$ top soil). Pots were placed on $38-\mathrm{cm}$ (15.0-inch) high benches. Bench sections of $0.9 \times 3.7 \mathrm{~m}(3 \times 12 \mathrm{ft})$ and $2.1 \times 3.7 \mathrm{~m}(7 \times 12 \mathrm{ft})$ on size were arranged alternately along the length of the greenhouse. There were 40-cm (15.7-inch) wide walkways between the alternate benches. Three and seven rows of pots were placed on the $1-\mathrm{m}(3.3 \mathrm{ft})$ or $2-\mathrm{m}(6.6 \mathrm{ft})$ wide benches, respectively. Plants were hand watered four times per day to minimize the heat stress under desert conditions. Nutrients were supplied with diluted $20 \mathrm{~N}-2.2 \mathrm{P}-8.3 \mathrm{~K}$ plus complete micronutrients.

LEDs AND LED CLIP ATTACHMENTS. The 10-lumen lime green LEDs (Nichia NSPPG500S, Nichia America Corp., Mountville, Pa.) used in the experiments were energized with 220 ohm resistors via a $6-\mathrm{V}$ direct-current adaptor (Radio Shack Co., Fort Worth, Texas). The adaptor was connected to a standard $110-\mathrm{V}$ alternating current electricity source. The LED clip had two LEDs, with each one wired to a 2 $\mathrm{cm}$ (0.8-inch) long piece of perforated circuit board. The circuit boards with LEDs were attached with screws to the tips of the two arms of an $8.5-\mathrm{cm}$ (3.35-inch) long hair clip. The LED clips were fit on YC traps with one LED on each side of the YC trap.
Experimental Design. The experimental design was paired treatments in 10 replicates. Treatments were LED-YC and standard YC traps, which were arranged alternately and $122 \mathrm{~cm}$ (48.0 inches) apart. YC traps were 15 $\times 30 \mathrm{~cm}(5.9 \times 11.8$ inches $)$ with 440 $\mathrm{cm}^{2}\left(68.2\right.$ inch $\left.^{2}\right)$ in sticky surface area on each side of the trap. LED-YC and YC traps were suspended on horizontal wires above the plants. The distance between the bottom edge of the traps and the top of poinsettia plants was about $100 \mathrm{~cm}$ (39.4 in). During the study, plants grew from $10 \mathrm{~cm}(3.9$ inches) to $47 \mathrm{~cm}$ (18.5 inches) tall, and from a few leaves to several levels of leaves covering whole benches. Traps were retrieved and replaced with new cards weekly. The area on each side of a trap was divided into three rows of three equal size squares. Three diagonal squares on each side of the trap were randomly selected and the captured insects identified and counted under a stereoscope.

Temperature and humidity in the greenhouse were monitored with two sensor data loggers (Hobo, Onset Computer Co., Pocasset, Mass.) at 2$\mathrm{h}$ intervals. During the experimental period, the daily low temperature ranged from 14.1 to $25.2^{\circ} \mathrm{C}$ ( 57.38 to $77.36{ }^{\circ} \mathrm{F}$ ), high temperature 26.7 to $47.9^{\circ} \mathrm{C}\left(80.06\right.$ to $\left.118.22^{\circ} \mathrm{F}\right)$, low RH $21.8 \%$ to $37.9 \%$, and high $\mathrm{RH}$ $30.3 \%$ to $100 \%$. Various insecticides, including pyrethroids, insect growth regulators, and neem derivatives, were sprayed alternately at weekly intervals during the experimental period.

Data analysis. The numbers of insects caught on the sticky card traps were analyzed using $t$-tests (SAS Institute, 2000). The significance level was $P=0.05$.

\section{Results and discussion}

InSECT IDENTIFICATION. Insect pests caught on the YC and LED-YC traps included: sweet potato whiteflies biotype B (Homoptera: Aleyrodidae), dark-winged fungus gnats (Diptera: Sciaridae), western flower thrips (Thysanoptera: Thripidae), and leafhoppers (Homoptera: Cicadellidae). The beneficial insects captured included: minute pirate bugs, (Hemiptera: Anthocoridae), parasitic wasps ( $\mathrm{Hy}-$ menoptera) and rove beetles (Coleoptera: Staphylinidae). Other insect species caught included: antlike flower beetles (Ischyropalpussp.) (Coleoptera: 
Anthicidae), flies (Diptera), and a few miscellaneous unidentified species.

Pest insect captures. Darkwinged fungus gnats. The weekly average numbers of dark-winged fungus gnats captured on LED-YC traps were greater compared with on YC traps over the 24 weekly samples. Significant differences between LED-YC and YC traps occurred in 21 weekly samples $(t$ $=2.22-11.31 ; P=<0.0001-0.0402$ ) (Fig. 1). Over the 24 weeks of the experiment, a total of 9183 dark-winged fungus gnats were caught per LEDYC trap, compared with 1729 caught per YC trap $(t=10.72 ; P=0.0001)$ (Table 1).

Sweet potato whiteflies. LED-YC traps captured more sweet potato whiteflies compared with YC traps in 18 out of the 24 weekly samples. Significant differences occurred in 9 weekly samples $(t=1.99-3.80 ; P=$ 0.0013-0.0179) (Fig. 2). Over the 24 weeks of the experiment, a total 73,302 sweet potato whiteflies were caught per LED-YC trap, compared with 53,187 caught per YC trap ( $t=$ $2.75 ; P=0.0132$ ) (Table 1$)$.

Leafhoppers. LED-YC traps captured more leafhoppers compared with YC traps in 21 out of the 24 weekly samples. Significant differences occurred in 10 weekly samples $(t=$ 1.92-3.73; $P=0.002-0.038$ ) (Fig. $3)$. Over the 24 weeks of the experiment, a total of 57 leafhoppers were caught per LED-YC trap, compared with 6 caught per YC trap $(t=4.42$; $P=0.0003$ ) (Table 1 ), and the ratio was 5.0.

Western flower thrips. LED-YC traps captured more western flower thrips compared with YC traps in 15 out of the 24 weekly samples. Significant differences were found in 10 weekly samples $(t=1.75-6.82 ; P$ $=0.0277$ to $<0.0001$ ) (Fig. 4). Over the 24 weeks of the experiment, a total of 543 western flower thrips were caught per LED-YC trap, compared with 488 caught per YC trap, but the difference was nonsignificant $(t=1.15$; $P=0.2644$ ) (Table 1). The results for western flower thrips agree with a previous report (Chu et al., 2002). Several reports indicated that thrips including western flower thrips were attracted to the color blue (Brodsgaard, 1993; Chu et al., 2000; Gaum and Giliomee, 1994; Matteson and Terry, 1992; Yudin et al., 1987). Additional studies need to be undertaken to determine the

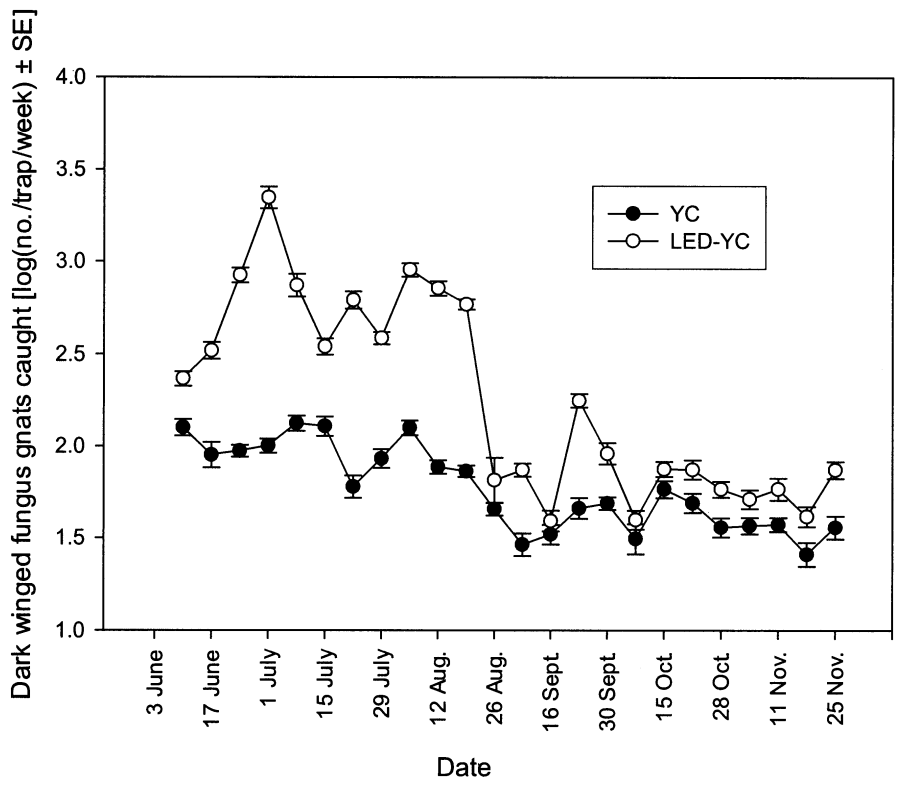

Fig. 1. Seasonal number of dark-winged fungus gnats caught in a poinsettia greenhouse with YC = standard yellow sticky card traps, and LED-YC = lightemitting diode modified yellow sticky card traps.

Table 1. Numbers of pest and beneficial insects caught per light-emitting-diodemodified yellow sticky card (LED-YC) trap and yellow sticky card (YC) trap in 24 weeks in a poinsettia greenhouse.

\begin{tabular}{lccrrr}
\hline & \multicolumn{2}{c}{ Insects caught } & & \\
\cline { 2 - 3 } Insect & (no./LED-YC trap) & (no./YC trap) & & $\boldsymbol{t}$ & $\boldsymbol{P}$ \\
\hline Sweet potato whiteflies & $73302 \pm 3515 \mathrm{a}^{\mathrm{z}}$ & $53187 \pm 6413 \mathrm{~b}^{\mathrm{z}}$ & 2.75 & 0.0132 \\
Dark winged fungus gnats & $9183 \pm 683 \mathrm{a}$ & $1729 \pm 127 \mathrm{~b}$ & 10.72 & 0.0001 \\
Leafhoppers & $57 \pm 11 \mathrm{a}$ & $6 \pm 1 \mathrm{~b}$ & 4.42 & 0.0003 \\
Western flower thrips & $543 \pm 19 \mathrm{a}$ & $488 \pm 42 \mathrm{a}$ & 1.15 & 0.2644 \\
Minute pirate bugs & $19 \pm 4 \mathrm{a}$ & $28 \pm 4 \mathrm{a}$ & 1.54 & 0.1421 \\
Parasitic wasps & $142 \pm 8 \mathrm{a}$ & $126 \pm 11 \mathrm{a}$ & 1.13 & 0.2719 \\
Rove beetles & $26 \pm 1 \mathrm{a}$ & $2 \pm 1 \mathrm{~b}$ & 11.98 & 0.0001 \\
\hline
\end{tabular}

${ }^{2}$ Means in the same row followed by the different letters are significantly different at $P=0.05$ ( $t$-test).

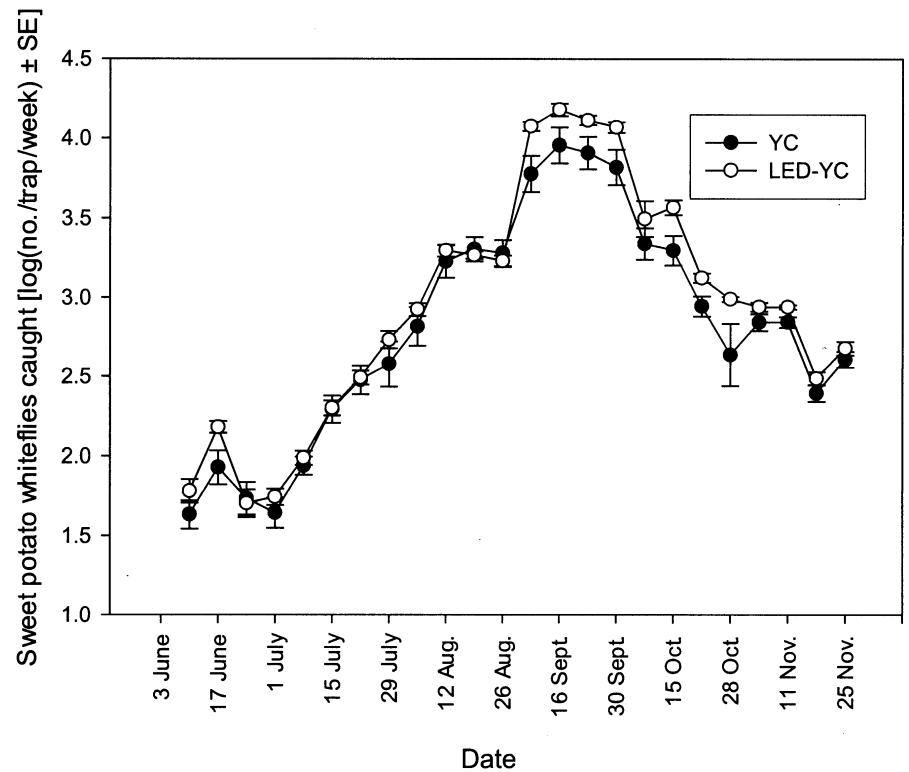

Fig. 2. Seasonal number of sweet potato whiteflies caught in poinsettia greenhouse with YC = standard yellow sticky card traps, and LED-YC = light-emitting diode modified yellow sticky card traps. 
attractant potential of blue LED-YC traps to western flower thrips.

BENEFICIAL INSECT CAPTURES. Minute pirate bugs. Minute pirate bugs were captured during June and August (Fig. 5). Over the 24 weeks of the experiment, a total of 19 minute pirate bugs were caught per LED-YC trap, compared with 28 caught per YC trap. The difference was nonsignificant (Table 1) $(t=1.54 ; P=0.1421)$.

Parasitic wasps. Among the 24 weekly samples, LED-YC traps captured significantly more wasps than YC traps in 8 weekly samples $(t=$ $1.35-2.95 ; P=0.009-0.025)$, fewer in three weekly samples $(t=1.77-3.66 ; P$ $=0.002-0.045)$. There were no significant differences between LED-YC and YC trap catches for 13 weekly samples (Fig. 6). Over the 24 weeks of the experiment, a total of 142 wasps were caught per LED-YC trap, compared with 126 caught per YC trap (Table $1)$. The difference was nonsignificant $(t=1.13 ; P=0.2719)$.

Rove beetles. The LED-YC traps captured more rove beetles compared with YC traps in 12 out of the 24 weekly samples $(t=1.81-5.25 ; P=$ $<0.0001-0.0382$ ) (Fig. 7). Over the 24 weeks of the experiment, a total of 26 rove beetles were caught per LED-YC trap, compared with 2 caught per YC trap $(t=11.98, \mathrm{P}=0.0001)$ (Table 1).

Summary. Over the 24 weeks of the experiment, LED-YC traps captured more dark-winged fungus gnats, sweet potato whiteflies biotype B, leafhoppers, and rove beetles compared with YC traps. Capture of western flower thrips, minute pirate bugs, and parasitic wasps were not significantly

Fig. 3 (тор). Seasonal number of leafhoppers caught in a poinsettia greenhouse with $\mathrm{YC}=$ standard yellow sticky card traps, and LED-YC = light-emitting diode modified yellow sticky card traps.

Fig. 4 (MIDDLE). Seasonal number of western flower thrips caught in a poinsettia greenhouse with $\mathrm{YC}=$ standard yellow sticky card traps, and LED-YC = light-emitting diode modified yellow sticky card traps

Fig. 5 (воттом). Seasonal number of minute pirate bugs caught in a poinsettia greenhouse with $\mathrm{YC}=$ standard yellow sticky card traps, and LED-YC = light-emitting diode modified yellow sticky card traps.
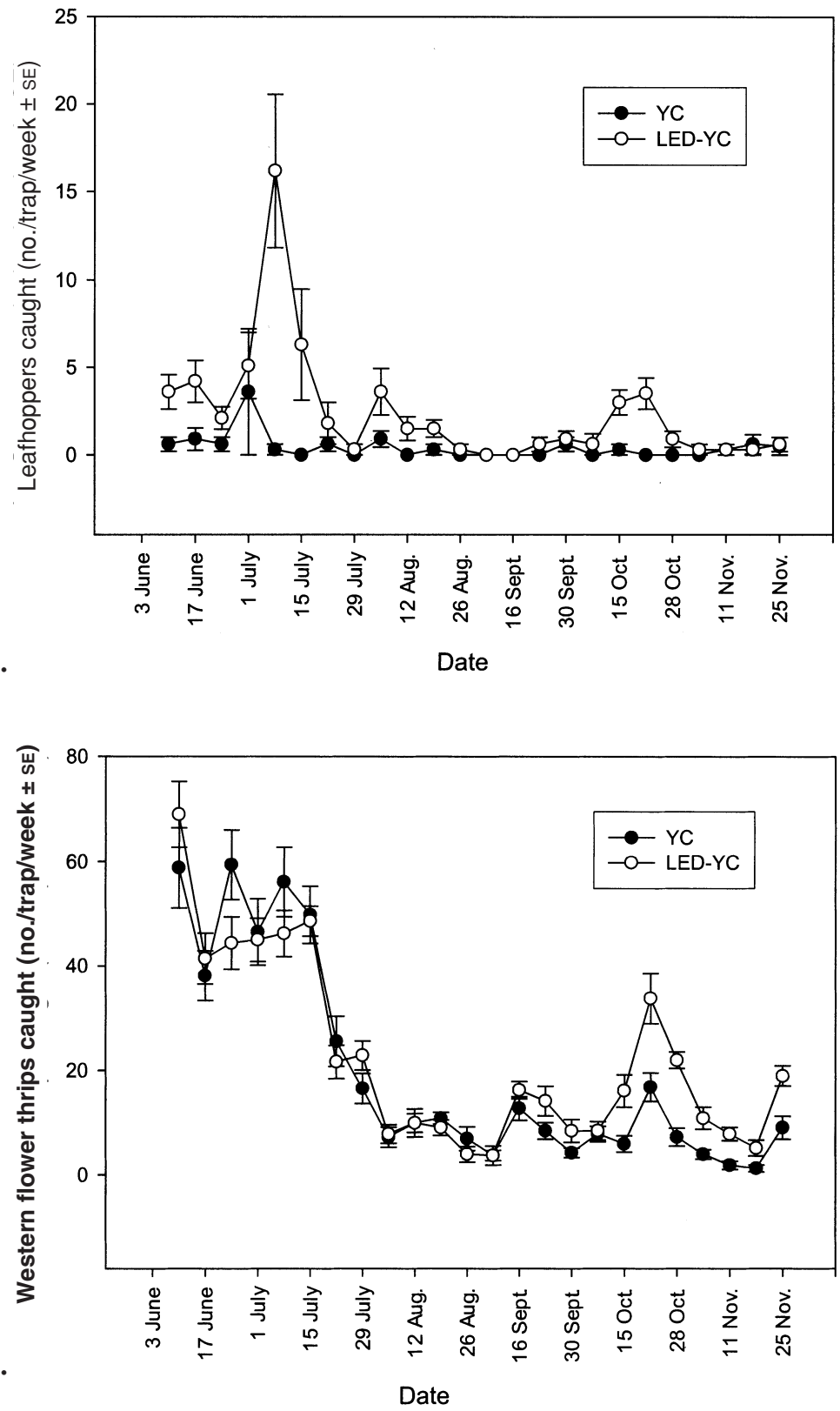

Fig. 4.

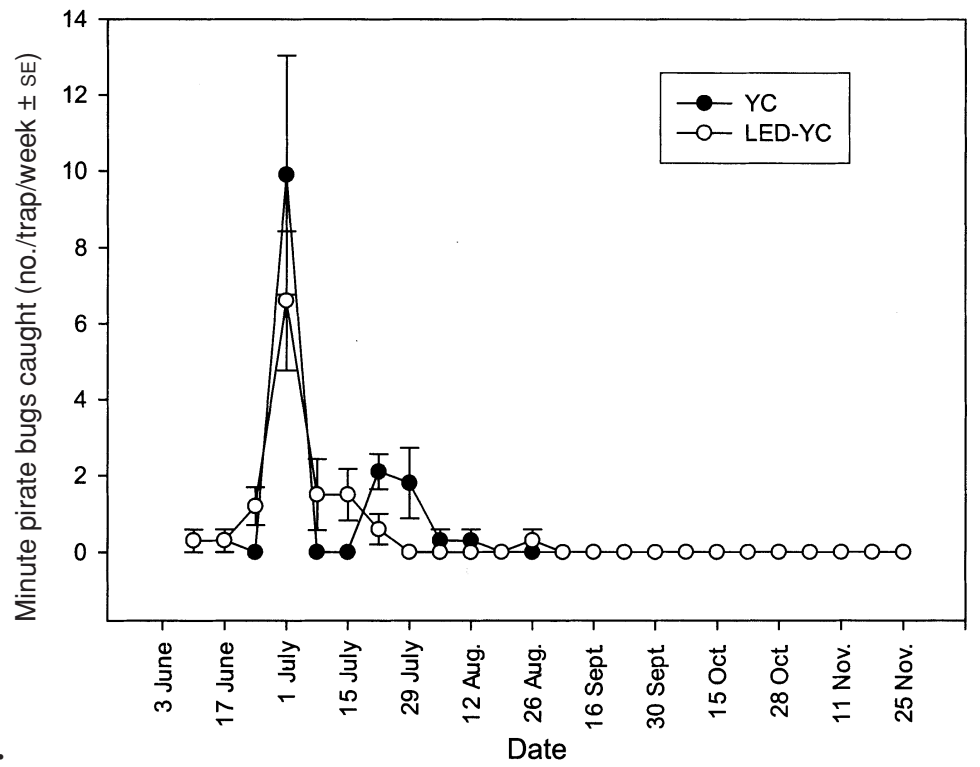




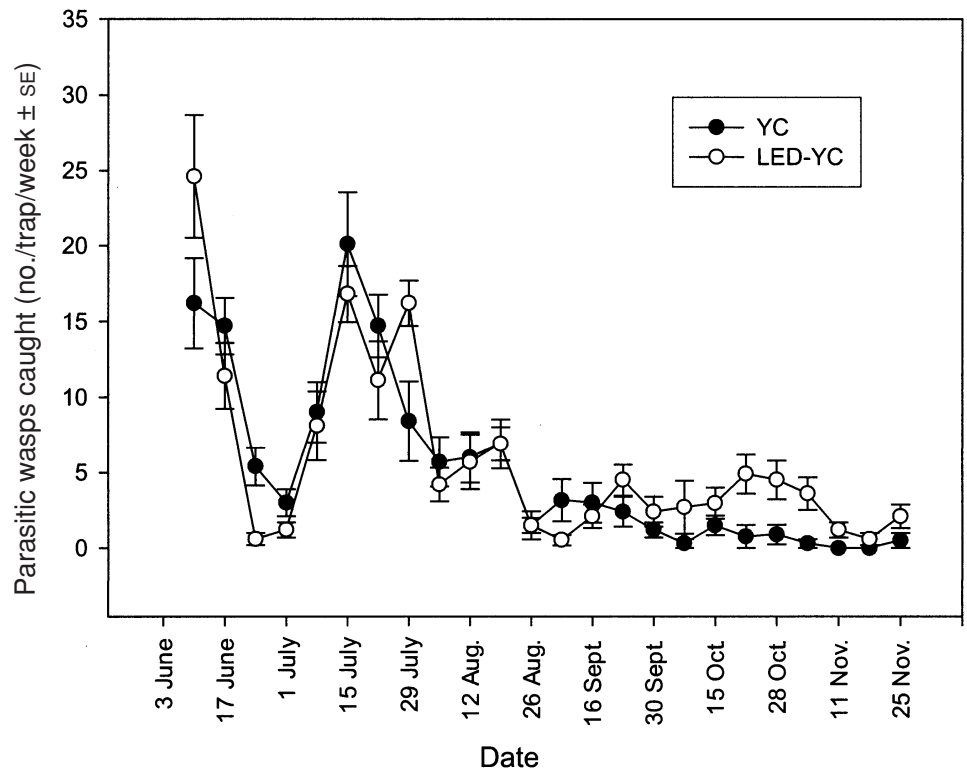

Fig. 6. Seasonal number of parasitic wasps caught in a poinsettia greenhouse with YC = standard yellow sticky card traps, and LED-YC = light-emitting diode modified yellow sticky card traps.

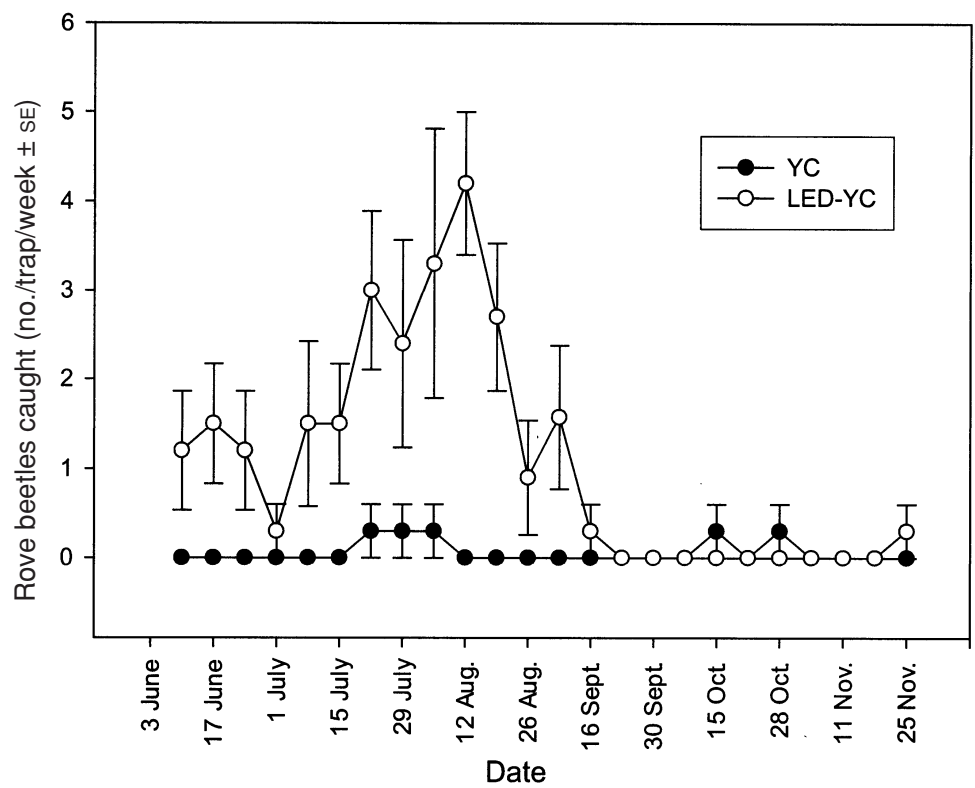

Fig. 7. Seasonal number of rove beetles caught in a poinsettia greenhouse with YC = standard yellow sticky card traps, and LED-YC = light-emitting diode modified yellow sticky card traps.

increased on the YC traps equipped with LEDs. The results indicate that the LED-YC traps attract three major pest insects in poinsettia greenhouses and do not catch more beneficial, minute pirate bugs and parasitic wasps, but may catch significant number of rove beetles. LED-YC traps maybe a useful monitoring and trapping tool in greenhouses but additional work is needed to quantify their effect on pest populations.

Brodsgaard, H.F. 1993. Coloured sticky traps 16:19-22. Control Assoc. 14:186-195. equipped with light-emitting diodes for monitoring adult Bemisia tabaci (Homoptera: Aleyrodidae). J. Econ. Entomol. 96(3):543-546.

Chu, C.C., P.J. Pinter, Jr., T.J. Henneberry, K. Umeda, E.T. Natwick, Y. Wei, V.R. Reddy, and M. Shrepatis. 2000. Use of CC traps with different trap base colors for silverleaf whiteflies (Homoptera: Aleyrodidae), Thrips (Thysanoptera: Thripidae), and Leafhoppers (Homoptera: Cicadellidae). J. Econ. Entomol. 93:1329-1337.

Chu, C.C., A.M. Simmons, P.J. Alexander, and T.J. Henneberry. 2002. A light-emitting diode equipped yellow sticky card trap, p. 209. In: T.J. Henneberry, R.M. Faust, W.A. Jones, and T.M. Perring (eds.). Silverleaf whitefly national research, action, and technology transfer plan: Fourth annual review of the S2nd 5-year plan and final report for 1992-2002: 209 USDA/ CSRS, ARS, 2002.

Ekbon, B.S. and R. Xu. 1990. Sampling and spatial patterns of whiteflies, p. 107-121. In:D. Gerling (ed.). Whiteflies: Their bionomics, pest status and management. Intercept, Andover, U.K.

Gaum, W.G. and J.H. Giliomee. 1994. Preference of western flower thrips, Frankliniella occidentalis (Thysanoptera: Thripidae), and greenhouse whitefly, Trialeurodesvaporariorum (Hemiptera: Aleyrodidae), for differently coloured sticky traps. J. S. Afr. Soc. Hort. Sci. 4:39-41.

Gillespie, D.R. and D. Quiring. 1987. Yellow sticky traps for detecting and monitoring greenhouse whitefly (Homoptera: Aleyrodidae) adults on greenhouse tomato crops. J. Econ. Entomol. 80:675-679.

Gillessen, K. and W. Schairer 1987. Light emitting diodes: An introduction. Prentice-Hall. Englewood Cliffs, N.J.

Knutson, A, and J. Ruberson. 1996. Field guide to predators, parasites and pathogens attacking insect and mite pests of cotton. Texas Agr. Ext. Ser., College Station.

Matteson, N.A. and L.I. Terry. 1992. Response to color by male and female Frankliniella occidentalis during swamming and non-swamming behavior. Entomol. Expt. Appl. 2:187-201

SAS Institute. 2000. SAS/STAT user's guide. SAS Inst., Cary, N.C.

Schubert, E.F. 2003. Light-emitting diodes. Cambridge Univ. Press, Cambridge, U.K.

Schubert, E.F. and H.W. Yao. 2002. Lightemitting diode: Research, manufacturing, and applications. VI. SPIE. Bellingham, Wash.

van de Veire, M. and V. Vacante. 1984. Greenhouse whitefly control through the combined use of colour attraction system with the parasite wasp Encarsia formosa (Hym.: Aphelinidae). Entomophaga 29:303-310. for thrips (Thysanoptera: Thripidae) monitoring on glasshouse cucumbers. Bul. IOBC-WPRS

Burkett, D.A., J.F. Butler, and D.L. Kline. 1998. Field evaluation of colored light-emitting diodes as attractants for woodland mosquitoes and other Diptera in north central Florida. J. Amer. Mosq.

Chu, C.C., C.G. Jackson, P.J. Alexander, K. Karut, and T.J. Henneberry, 2003. Plastic cup traps
Weber, R.G. 1989. Response of larval Culex pipiens (Diptera: Culicidae) to light produced by light emitting diodes. Entomol. News 100:104-110.

Yudin, L.S., W.C. Mitchell, and J.J. Cho. 1987. Color preference of thrips (Thysanoptera: Thripidae) with reference to aphids (Homoptera: Aphididae) and leafminers in Hawaiian lettuce farms. J. Econ. Entomol. 80:51-55. 